\title{
Alkali Metal Ion Complexation of Adamantane Functionalized Diaza-bibracchial Lariat Ethers ${ }^{\dagger}$
}

\author{
Tatjana Šumanovac Ramljak, ${ }^{a}$ Kata Mlinarić-Majerski, ${ }^{a, *}$ and Branimir Bertoša ${ }^{\mathrm{b}}$ \\ ${ }^{a}$ Department of Organic Chemistry and Biochemistry, Ruđer Bošković Institute, \\ Bijenička cesta 54, P. O. Box 180, 10002 Zagreb, Croatia \\ ${ }^{\mathrm{b}}$ Division of Physical Chemistry, Department of Chemistry, Faculty of Science, Horvatovac 102A, 10000 Zagreb, Croatia
}

RECEIVED JUNE 15, 2012; REVISED NOVEMBER 27, 2012; ACCEPTED DECEMBER 4, 2012

\begin{abstract}
A series of adamantane functionalized diaza-lariat ethers 1-6 have been prepared and alkali metal picrate extraction profiles determined. The ability of aza-crown ethers 1-6 to extract the alkali metal picrates was compared with that of diaza-18-crown-6 (7) and $N, N^{\prime}$-dibenzodiaza-18-crown-6 (8). $\mathrm{Na}^{+}$and $\mathrm{K}^{+}$transport across bulk liquid membrane was also measured. The results of alkali metal cation extraction experiments showed that lariat ethers $\mathbf{2}$ and $\mathbf{3}$, in which the adamantane molecule is linked to the diaza-18crown- 6 by amine bond, have better complexation abilities for all cations compared to the parent crown ethers $\mathbf{7}$ and $\mathbf{8}$, as well as a significantly higher selectivity for $\mathrm{K}^{+}$than diaza-18-crown-6. However, diazalariat ether 1 showed reduced, and 4-6 negligible extractability towards any of the alkali cations. Monte Carlo conformational analysis pointed to the importance of conformational flexibility of the investigated compounds for their extraction ability of alkali cations.(doi: $10.5562 / \mathrm{cca} 2100)$
\end{abstract}

Keywords: diaza-bibracchial lariat ethers, adamantane functionalized crown ethers, metal ion complexation, metal ion transport, Monte Carlo conformational search

\section{INTRODUCTION}

Since Pedersen discovered crown ethers as a new class of compounds with unusually powerful non-covalent cation binding properties, ${ }^{1}$ they have played an important role in a number of areas in chemistry, the most notable being their application as synthetic receptors for organic and inorganic cations, anions and neutral molecules. ${ }^{2}$ Many different modifications of crown ethers, such as changing the ring size, the kind of substituents, and the type of donor atoms, have been made to enhance their complexation properties. ${ }^{3}$ One of the structural modifications is the replacement of one or more ether oxygen atoms with nitrogen ${ }^{4}$ as well as the attachment of a side arm to the ligand. Such side armed crown ethers have been named lariat ethers. ${ }^{5}$ In addition, there are number of papers describing crown ethers which contain a polycyclic moiety. ${ }^{6}$ Incorporation of a rigid polycyclic molecule such as cubane, ${ }^{7}$ pentacycloundecane, ${ }^{8}$ 3,5-disubstituted-4oxaheksacy-clo $\left[5 \cdot 4 \cdot 1 \cdot 0^{2,6} \cdot 0^{3,10} \cdot 0^{5,9} \cdot 0^{8,11}\right]$ dodecane, ${ }^{9} \quad 2$ oxaadamantane $^{6 \mathrm{~b}, 10}$ and adamantane ${ }^{10 \mathrm{~b}, 11}$ into crown ethers should affect their conformational mobility and complexation abilities. The lipophilic polycyclic moiety is expected to increase the solubility of crown ethers in non- polar media and thereby increase their ability for metal ion complexation and ion transport. Because of their structural characteristics, crown ether compounds exhibit ionophoric properties in membranes, behaving very similarly to the natural ionophores (such as gramicidin, valinomycin, nonactin, etc.) which makes them particularly interesting and useful. ${ }^{12}$ Beyond their traditional place in chemistry, their applications in biology include the ability to regulate enzyme activity, ${ }^{12,13}$ interact with and cleave DNA, ${ }^{12,14,15}$ and act as antimicrobial agents. ${ }^{14-16}$

In this paper we describe the cation binding properties of six highly lipophilic diaza-18-crown-6 derivatives with adamantane moieties attached to the side arms: $N, N$ '-bis(1-adamantylmethyl]-4,13-diaza-18-crown-6 (1), $N, N^{\prime}$-bis[2-(1-adamantyl)ethyl]-4,13-diaza-18-crown-6 (2), $N, N$ '-bis[3-(1-adamantyl)propyl]-4,13-diaza-18-crown6 (3), $N, N^{\prime}$-bis(1-adamantanoyl)-4,13-diaza-18-crown-6 (4), $N, N^{\prime}$-bis[1-oxo-2-(1-adamantyl)ethyl]-4,13-diaza18-crown-6 (5) and $N, N^{\prime}$-bis[1-oxo-3-(1-adamantyl)propyl]-4,13-diaza-18-crown-6 (6). In diaza-bibracchial lariat ethers 1, 2 and 3 the linkage between adamantane moieties and diaza-18-crown-6 is accomplished by using an alkyl chain of different length while in the compounds $\mathbf{4}, \mathbf{5}$ and $\mathbf{6}$ by using the amide bond linkage.

\footnotetext{
$\dagger$ This article belongs to the Special Issue devoted to the $85^{\text {th }}$ anniversary of Croatica Chemica Acta.

* Author to whom correspondence should be addressed. (E-mail: majerski@irb.hr)
} 
The presence of a $\mathrm{C}=\mathrm{O}$ linkage should impose rigidity and preorganization of the receptor, but is also expected to strongly reduce the binding properties of nitrogen atom of the macrocyclic ring. ${ }^{11}$ In the case of methylene linkage, complexation ability of nitrogen atom is preserved, but the resulting ligand is more flexible. In an attempt to rationalize the experimental results and to investigate relationship between conformational flexibility and extraction properties of crown compounds 1-6, we performed conformational analysis of investigated compounds using Monte Carlo algorithm. This kind of calculations has already proven as successful in similar investigations. ${ }^{17,18}$

\section{EXPERIMENTAL}

\section{Extraction Experiments}

The extraction experiments were performed similarly as was reported elswere. ${ }^{10,19}$ Each of the alkali metal $\left(\mathrm{Li}^{+}\right.$, $\mathrm{Na}^{+}, \mathrm{K}^{+}, \mathrm{Rb}^{+}$, and $\mathrm{Cs}^{+}$) picrates were freshly prepared by reacting the respective alkali metal hydroxides, $\mathrm{M}^{+} \mathrm{OH}^{-}$, with picric acid. ${ }^{19} \mathrm{Li}^{+}$picrate was prepared and subsequently used in situ due to its high solubility in water and EtOH. All other alkali metal picrates were isolated and dried prior to use. A $5.0 \mathrm{mM}$ aqueous solution of all alkali metal picrate was prepared. Reagent grade $\mathrm{CHCl}_{3}$ was washed three times with redistilled water and then utilized to prepare $5.0 \mathrm{mM}$ solution of diaza crown ethers 1-6. A $\mathrm{CHCl}_{3}$ solution $(0.5 \mathrm{~mL})$ of the corresponding crown ether was placed into a $5 \mathrm{~mL}$ screw-top vial, and the aqueous solution of the alkali metal picrate $(0.5 \mathrm{~mL})$ was added. Another portion of the metal picrate solution $(0.5 \mathrm{~mL})$ was added to the second vial which contained $\mathrm{CHCl}_{3}(0.5 \mathrm{~mL})$, and no host (blank probe). The vials were stoppered, shaken on a Termolyne Maxi-Mix III Type 65800 mixer for 4 min, and then allowed to stand at ambient temperature for 1 h. A $0.1 \mathrm{~mL}$ aliquot of the aqueous phase was taken with automatic pippete and diluted in volumetric flask via addition of redistilled water to a total volume of 10 $\mathrm{mL}$. UV-Visible spectra were obtained for the two solutions, and the percent of picrate extracted in each case was calculated from the absorbance measured on $355 \mathrm{~nm}$. For each combination of crown ether and alkali metal picrate, the picrate extraction was conducted on five different samples, and the average value of percent picrate extracted was calculated. ${ }^{10}$ In the absence of crown ether, no metal picrate extraction was detected.

Transport of Alkali Metal Picrates across Bulk Chloroform Membranes

The transport studies were conducted at ambient temperature in "hollow-tube-within-a-vial“ cells as reported earlier. ${ }^{10 b, 20}$ A hollow glass tube $(20 \mathrm{~mm}$ ID) was suspended vertically within a glass vial (40 mm ID) so that the bottom of the glass tube extended below the surface of the $\mathrm{CHCl}_{3}$ membrane which separated the aqueous source phase $\left(3 \mathrm{~mL}\right.$ of $2.5 \times 10^{-3} \mathrm{M}$ solution of alkali metal picrate in redistilled water) from aqueous receiving phase $(10 \mathrm{~mL}$ of redistilled water). The liquid membrane consisted of $10 \mathrm{~mL}$ of $\mathrm{CHCl}_{3}$ solution of crown ether $\left(c=0.075 \times 10^{-3} \mathrm{M}\right)$. The molar ratio of crown ether to alkali metal picrate was 1:10. The organic phase was stirred at ca. $200 \mathrm{rpm}$ by means of internal small magnetic stirring bar. During the first $7 \mathrm{~h}$, aliquot of the aqueous receiving phase $(3 \mathrm{~mL})$ was taken at $1 \mathrm{~h}$ intervals, and the concentration of alkali metal picrate was determined by recording the UV-visible spectra (percent of picrate transported was calculated from the absorbance measured on $355 \mathrm{~nm}$ with $\varepsilon=$ 14400). The aliquot was returned to the receiving phase and transport experiment was continued. Transport rate was calculated as a slope of moles of picrate transported $v s$. time data, fitted to a straight line. After the first $7 \mathrm{~h}$ transport experiment was continued for another $17 \mathrm{~h}$ (total of $24 \mathrm{~h}$ ), and the total amount of picrate transported in $24 \mathrm{~h}$ was determined.

\section{Computational Methods}

Conformational search was performed for compounds 1-6 and two referent compounds 7 and 8 using the software Macromodel $^{21}$ which enables efficient conformational search of cyclic compounds. The initial 3D molecular structures were obtained by submitting the smile codes to the online 3D structure generator (http://cactus.nci.nih.gov/translate/). Allinger's MM3 force field ${ }^{22}$ was used for parameterization of the molecules and solvent effect was modelled using the generalized Born-solvent accessible surface area continuum solvent model (GB/SA) for chloroform. ${ }^{23}$ For each compound, the conformational search was performed using at least 20000 steps of Monte Carlo multiple minimum (MCMM) procedure. In each step, generated conformation was initially energy minimised using 500 steps of Polak-Ribière conjugate gradient algorithm. The conformations that were found within $20 \mathrm{~kJ} / \mathrm{mol}$ from the energetically most favourable conformation were additionally energy minimised using 300 steps of Truncated Newton conjugate gradient algorithm. In order to make the search as extensive as possible, the conformation that has been found the least times (within $20 \mathrm{~kJ} / \mathrm{mol}$ from the most favourable conformation) was used as the starting one in the subsequent run. Even so, some conformations were found several tens of times leading to the conclusion that the conformational space was thoroughly sampled. Gromacs software $^{24}$ was used for cluster analysis which was performed on the set of conformations found within 10 $\mathrm{kJ} / \mathrm{mol}$ energy window. 


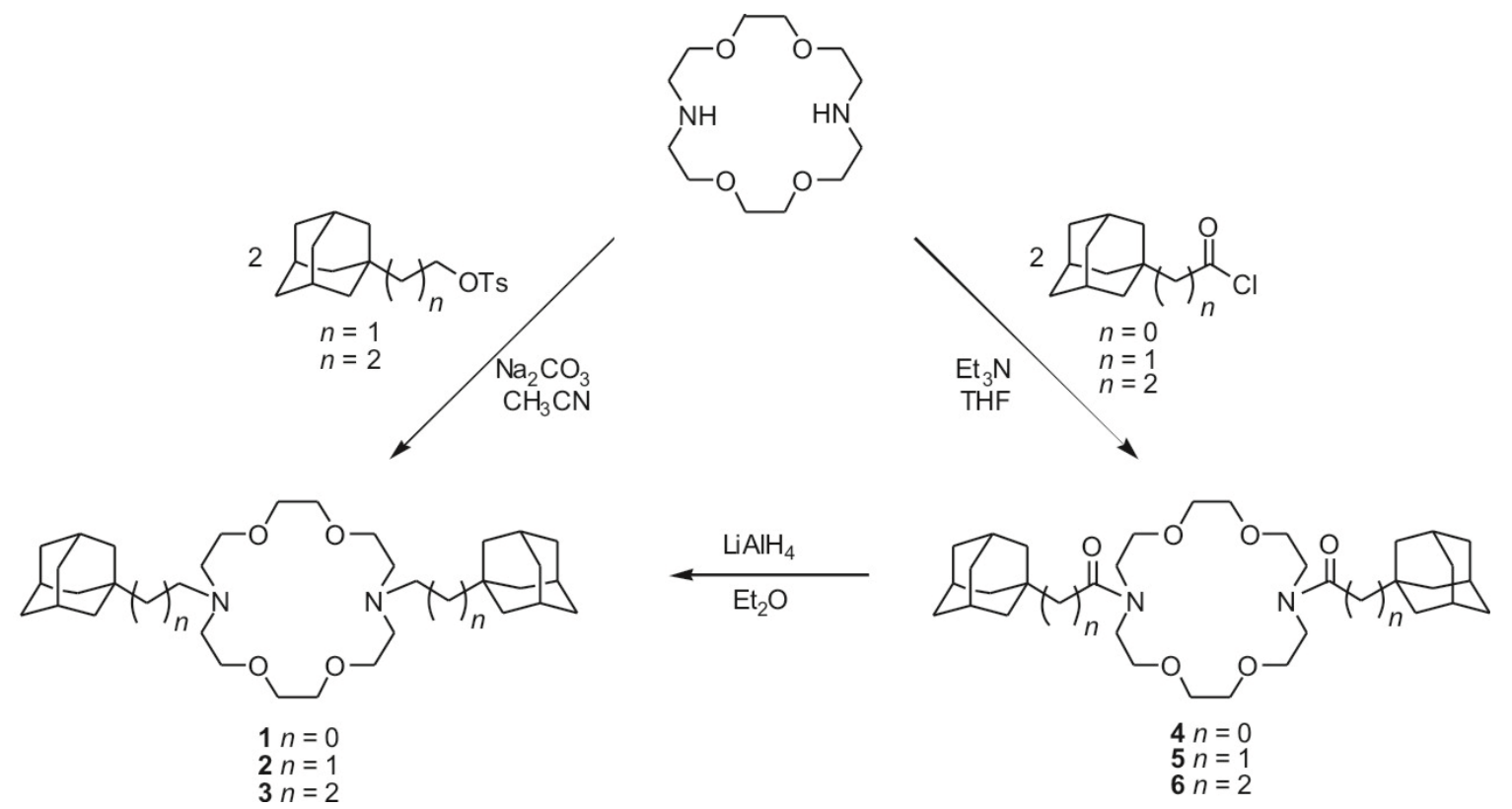

Scheme 1. Synthesis of diaza-bibracchial lariat ethers 1-6.

\section{RESULTS AND DISCUSSION}

The synthesis of diaza-bibracchial crown ethers $\mathbf{1}-\mathbf{3}$ was based on $N$-alkylation of diaza-18-crown- 6 with the corresponding adamantyl tosylates or the coupling reactions with two equivalents of corresponding acyl chlorides followed by reduction of the obtained crown ethers 4-6 with $\mathrm{LiAlH}_{4}$, as shown on Scheme $1 .{ }^{25}$ The corresponding adamantyl tosylates and adamantyl acyl chlorides were prepared according literature procedures. ${ }^{26}$ All the products were purified by column chromatography. It is important to point out that no mono-lariat ethers were observed in the reaction medium. The prepared lariat crown ethers 1-6 were characterized by their IR, ${ }^{1} \mathrm{H}$ NMR, and ${ }^{13} \mathrm{C}$ NMR spectral data as well as IR and HRMS. (Supplement S2-S20).

In order to investigate cation binding abilities of bibracchial lariat ethers 1-6, extraction experiments were carried out by solvent extraction of alkali metal picrates from aqueous solution into chloroform. The results thereby obtained were compared with the corresponding results for the referent compounds, namely diaza-18-crown-6 (7) and $N, N^{\prime}$-dibenzodiaza-18-crown6 (8). Since picrate ion concentrations can easily be determined by UV measurements, extractions of aqueous alkali metal picrates were carried out at room temperature with chloroform solutions of diaza-crown ethers 1-6. The obtained results are shown in Table 1 and Figure 1.

Table 1. Extractions of alkali picrates with $\mathrm{CHCl}_{3}$ containing diaza-crown ethers $\mathbf{1}-\mathbf{8}$

\begin{tabular}{crrrrr}
\hline \multirow{2}{*}{ Crown ethers } & \multicolumn{5}{c}{ Percent of picrate extracted / \% } \\
\cline { 2 - 5 } & \multicolumn{1}{c}{${ }^{(\mathrm{a})}$} \\
\hline $\mathbf{1}$ & \multicolumn{1}{c}{$\mathrm{Li}^{+}$} & \multicolumn{1}{c}{$\mathrm{Na}^{+}$} & \multicolumn{1}{c}{$\mathrm{K}^{+}$} & \multicolumn{1}{c}{$\mathrm{Rb}^{+}$} & $\mathrm{Cs}^{+}$ \\
$\mathbf{2}$ & $8.8 \pm 0.3$ & $5.2 \pm 0.7$ & $8.2 \pm 0.3$ & $6.0 \pm 0.5$ & $5.3 \pm 0.6$ \\
$\mathbf{3}$ & $22.5 \pm 0.3$ & $37.1 \pm 0.7$ & $57.0 \pm 0.6$ & $35.8 \pm 0.8$ & $39.4 \pm 0.8$ \\
$\mathbf{4}$ & $27.1 \pm 0.7$ & $25.0 \pm 0.6$ & $44.1 \pm 0.7$ & $23.8 \pm 0.7$ & $26.5 \pm 0.6$ \\
$\mathbf{5}$ & $0.5 \pm 0.3$ & $0.5 \pm 0.6$ & $2.1 \pm 0.3$ & $1.0 \pm 0.5$ & $0.6 \pm 0.5$ \\
$\mathbf{6}$ & $0.3 \pm 0.3$ & $0.6 \pm 0.4$ & $1.1 \pm 0.4$ & $0.5 \pm 0.5$ & $2.8 \pm 0.3$ \\
$\mathbf{7}$ & $0.2 \pm 0.1$ & $1.0 \pm 0.6$ & $0.3 \pm 0.1$ & $0.2 \pm 0.5$ & $0.5 \pm 0.4$ \\
$\mathbf{8}$ & $23.1 \pm 0.5$ & $20.8 \pm 0.3$ & $25.4 \pm 0.7$ & $10.3 \pm 0.3$ & $18.8 \pm 0.8$ \\
\hline
\end{tabular}

\footnotetext{
(a) Defined as percent of picrate extracted into organic phase. Each value is the average of five independent extraction experiments.

(b) The extraction experiments were performed by using $5 \times 10^{-3} \mathrm{M} \mathrm{CHCl}_{3}$ solution of the diaza-crown ethers studied and $5 \times 10^{-3} \mathrm{M}$ $\mathrm{H}_{2} \mathrm{O}$ solution of alkali metal picrates.
} 


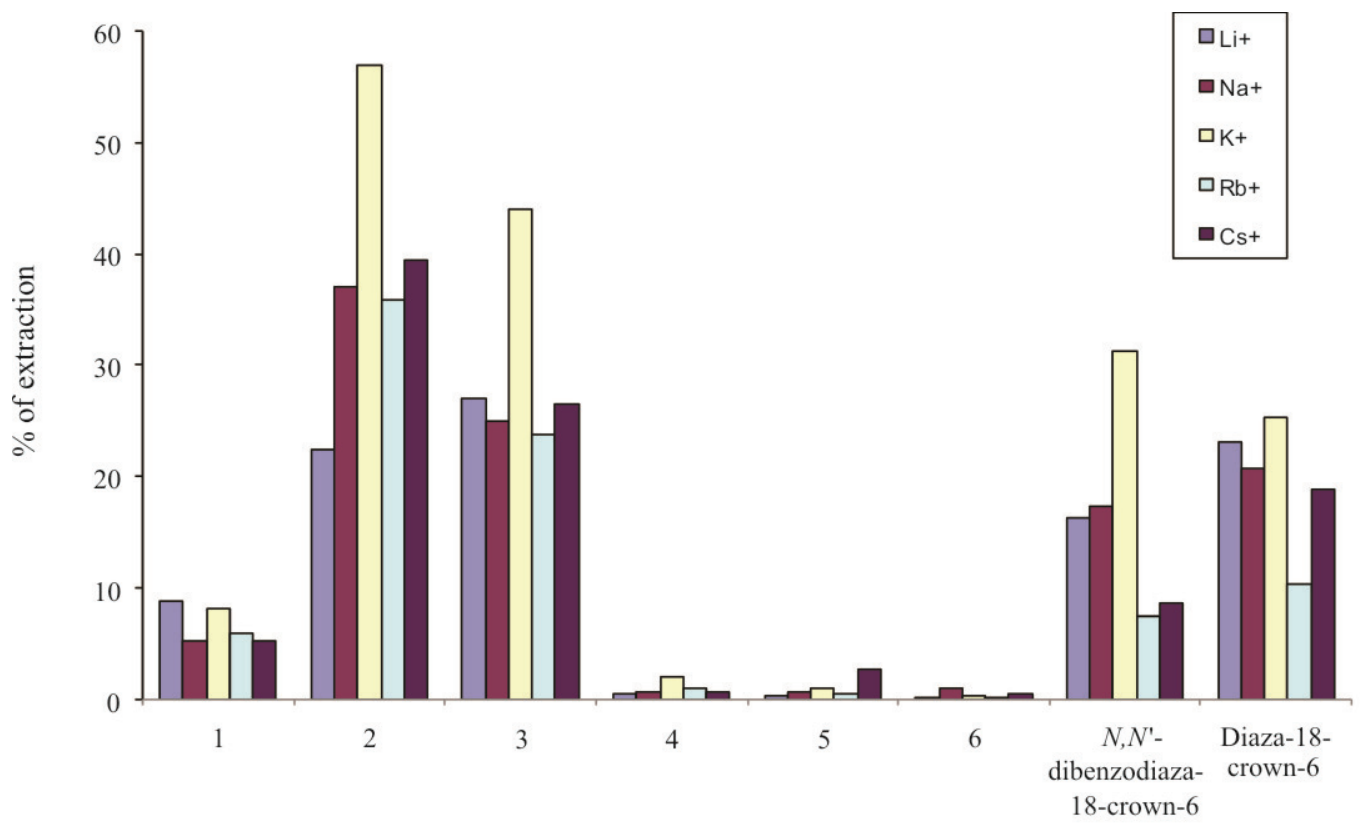

Crown ethers

Figure 1. Extraction of alkali picrates with $\mathrm{CHCl}_{3}$ containing diaza-crown ethers.

From the data shown in Table 1 and Figure 1, it is obvious that the lariat ethers $\mathbf{2}$ and $\mathbf{3}$ with the alkyl sidearms showed much better extraction towards all alkali cations, particularly $\mathrm{K}^{+}$, compared to the referent compounds. They both also showed a significantly higher selectivity towards $\mathrm{K}^{+}$than crown ether 7 , but lariat ether 2 showed slightly lower selectivity for $\mathrm{K}^{+}$than referent compound $\mathbf{8}$ in contrast to lariat ether $\mathbf{3}$ where the $\mathrm{K}^{+}$ selectivity is similar to the referent $N, N^{\prime}$-dibenzodiaza-18crown-6 (8). Lariat ether 1, which also contains an alkyl sidearm, displays an inferior ability to extract alkali metal picrates studied when compared with the extraction of model crown ethers 7 and $\mathbf{8}$. Similarly to the bibracchial lariat ether 1, ethers 4-6, with adamantane molecule linked through an amide bond, showed very low, almost negligible, extractions toward any of the alkali cations studied. It is apparent that the binding abilities of lariat crown ethers towards alkali metal cations are influenced by the chain length of the attached side arms and the type of the bonding to the nitrogen atom. This is in accord with our previously obtained results for the monosubstituted adamantane aza-crown ethers. ${ }^{11}$

Since diaza-crown ether $\mathbf{2}$ displayed a high affinity towards $\mathrm{Na}^{+}, \mathrm{K}^{+}, \mathrm{Rb}^{+}$, and $\mathrm{Cs}^{+}$cations when compared to parent diaza-18-crown-6 (7), we might assume that the high extraction is due to the formation of a relatively stable complexes with ionophore 2 and the metal cation guests.

\section{Conformational Analysis}

In order to rationalize experimental results, we performed the conformational analysis for the studied compounds 1-6. However, it is worth to note that the imposed rigidity for the crown ether $\mathbf{5} v s . \mathbf{2}$ and $\mathbf{6} v s . \mathbf{3}$ in the solution was observed by ${ }^{13} \mathrm{C}$ NMR spectra of those compounds (Figure 2 and Figure 3). Namely, in the aliphatic region $(46-71 \mathrm{ppm})$ in the spectra of crown ethers 5 and $\mathbf{6}$ there are 12 different signals corresponding to the carbon atoms $\mathrm{C}_{7 / 7^{\prime}}-\mathrm{C}_{12 / 12^{\prime}}$ for diaza-crown $\mathbf{5}$ (Figure 2a) and $\mathrm{C}_{8 / 8^{\prime}}-\mathrm{C}_{13 / 13}$, corresponding to diazacrown ether 6 (Figure 3a). Also there is the difference for the carbon atoms in the side-chain, as for $\mathrm{C}_{5}, \mathrm{C}_{6}, \mathrm{C}_{13}$, and $\mathrm{C}_{14}$ of diaza-crown ether 5 (Figure $2 \mathrm{a}$ ) and $\mathrm{C}_{5}, \mathrm{C}_{6}$, $\mathrm{C}_{7}, \mathrm{C}_{14}, \mathrm{C}_{15}$, and $\mathrm{C}_{16}$ of diaza-crown 6 (Figure $3 \mathrm{a}$ ). However, in the ${ }^{13} \mathrm{C}$ NMR spectra of diaza-crown ethers $\mathbf{2}$ and $\mathbf{3}$, only tree signals exist that correspond to the carbon atoms $\mathrm{C}_{7}, \mathrm{C}_{8}$, and $\mathrm{C}_{9}$ of diaza-crown 2 (Figure 2b) and $\mathrm{C}_{8}, \mathrm{C}_{9}$, and $\mathrm{C}_{10}$ of diaza-crown ether 3 (Figure $3 b)$. Also, there is no difference in the chemical shifts of the equivalent side-chain carbons in $\mathbf{2}$ (Figure $2 \mathrm{~b}$ ) and $\mathbf{3}$ (Figure $3 b$ ). Obviously the difference in the two sidearms as well as in the crown core of the diaza crown 5 and $\mathbf{6}$ is due to existence of stable unsymmetrical conformers on the NMR time-scale.

With the goal of investigating conformational space of the studied compounds Monte Carlo (MC) conformational search was performed. For each compound, $20000 \mathrm{MC}$ steps were accomplished. Since some of the conformers were found several tens of times (in some cases even more than hundred times), the selected number of steps was considered sufficient for extensive MC conformational search. In order to gain deeper insight into conformational distribution of investigated compounds, cluster analysis of MC results was 
(a)

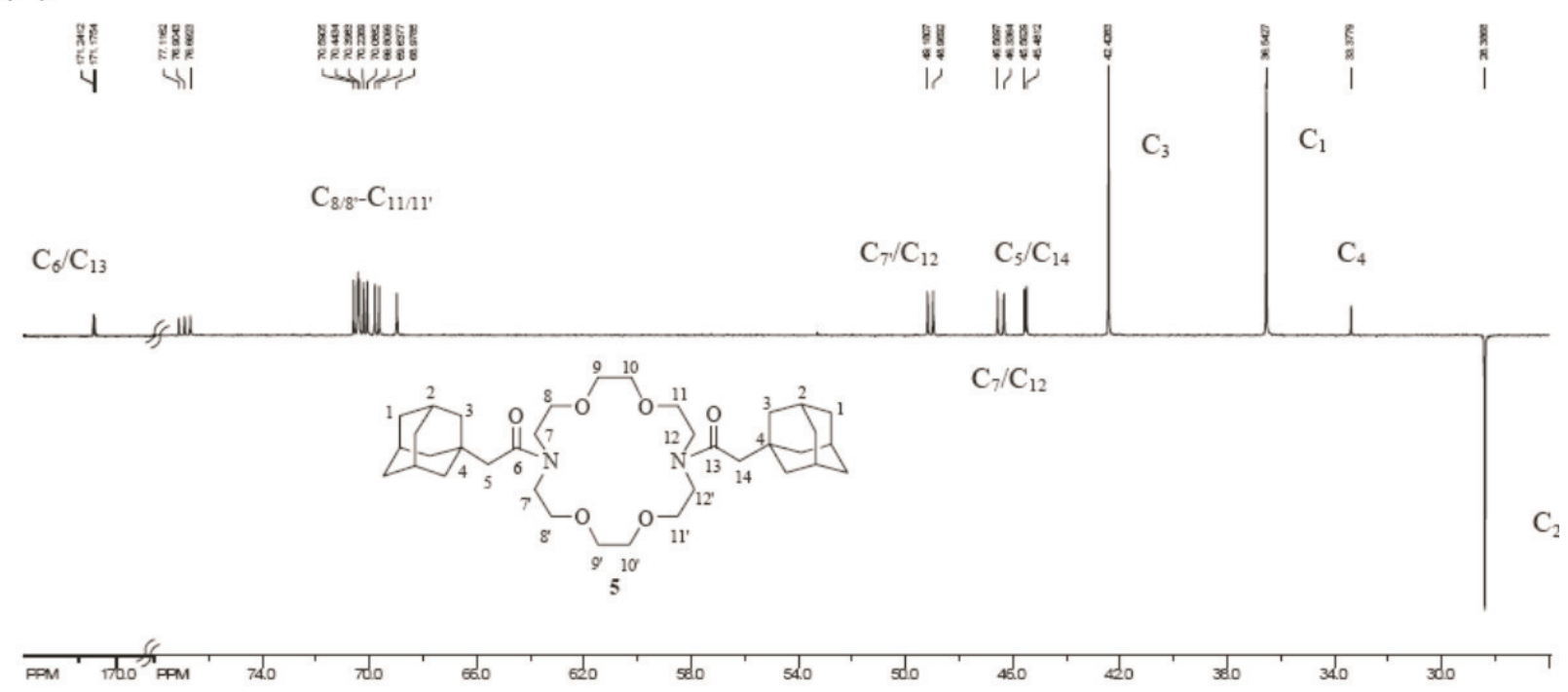

(b)

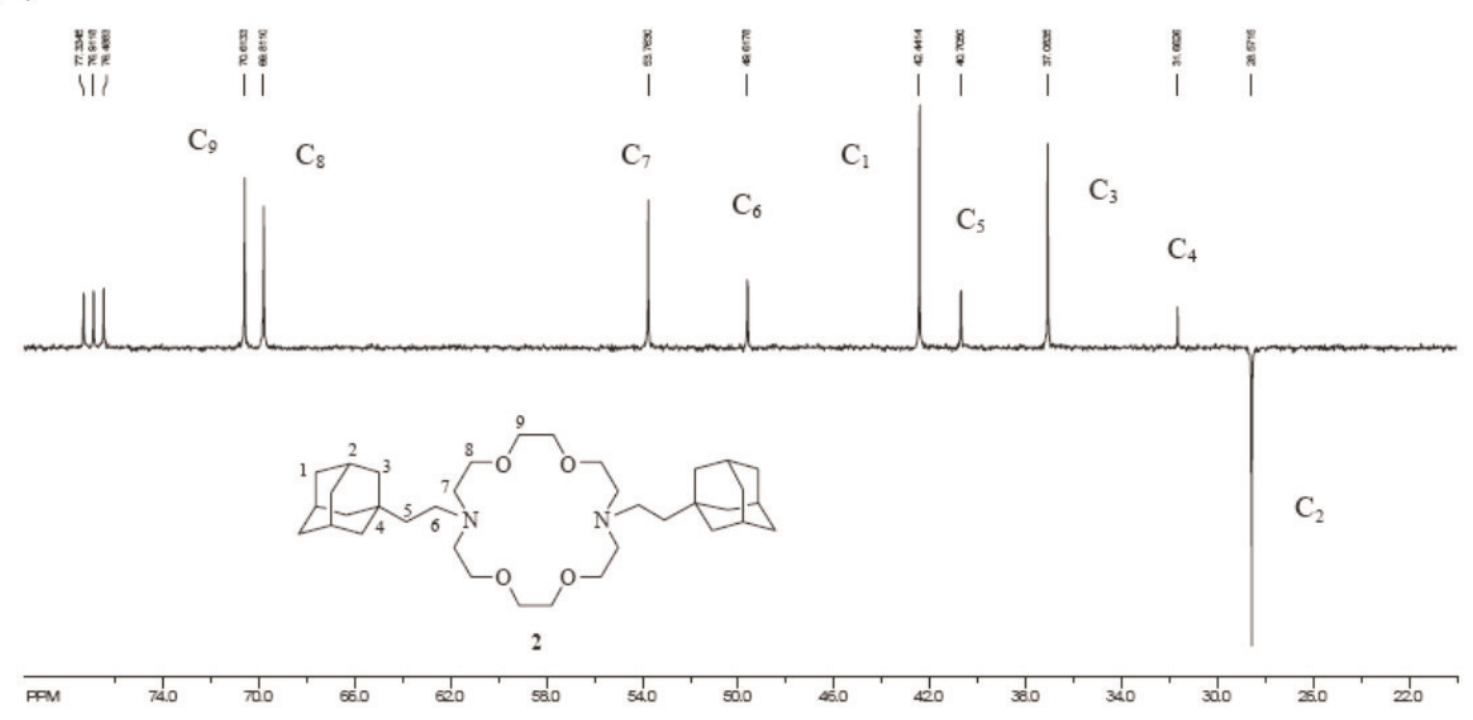

Figure 2. Comparison of the ${ }^{13} \mathrm{C}$ NMR spectra of lariat diaza-crown ethers $\mathbf{5}$ and $\mathbf{2}$.

performed. Special attention was given to the conformations that have oxygen and nitrogen atoms oriented in appropriate positions for binding alkali cation i.e. conformations that have oxygen and nitrogen atoms oriented towards the centre of the crown ether ring. Conformational flexibility was estimated through number of structures found within $10 \mathrm{~kJ} / \mathrm{mol}$ and $20 \mathrm{~kJ} / \mathrm{mol}$ energy windows and cluster analysis.

In case of the referent compound 7, conformational analysis was repeated with increased number of MC steps (150 000 steps) since the most favourable conformation was found less than dozen times during the $20000 \mathrm{MC}$ steps. However, conformational search with increased number of steps resulted with the same conformation as the global minimum. That conformation was found 356 times during the search being the 10 $\mathrm{kJ} / \mathrm{mol}$ more stable than any other conformation. This result leads to the conclusion that conformational space of diaza-18-crown-6 (7) is dominated by one very stable and, consequently, very populated conformation (1 structure within $10 \mathrm{~kJ} / \mathrm{mol}$ energy window, 20 structures within $20 \mathrm{~kJ} / \mathrm{mol}$, Table 2). Visual inspection of that conformation shows that 4 oxygen atoms are in appropriate position for binding alkali cation (Figure 4).

Conformational analysis of the other referent compound, $N, N$ '-dibenzodiaza-18-crown-6 (8), showed larger conformational flexibility (94 structures were found within $10 \mathrm{~kJ} / \mathrm{mol}$ energy window, 1214 structures 
(a)

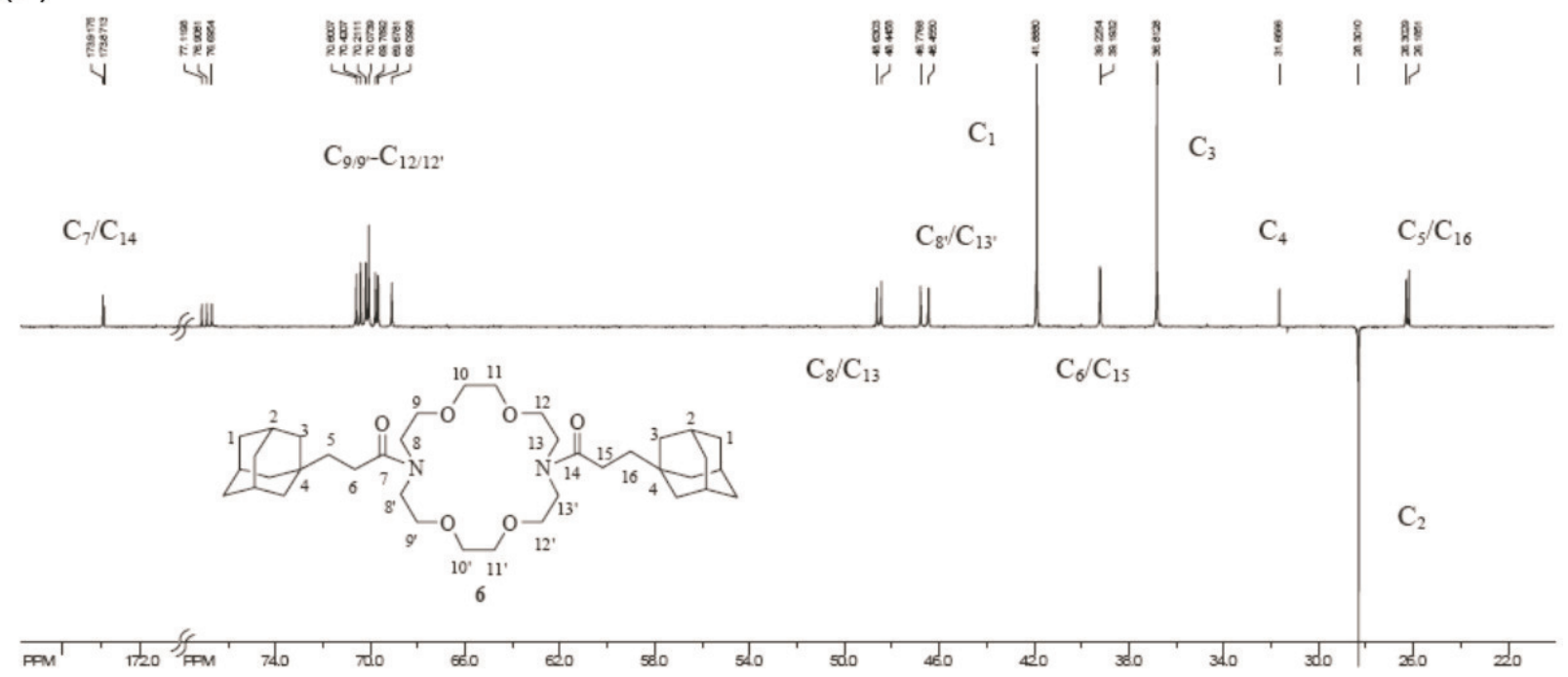

(b)
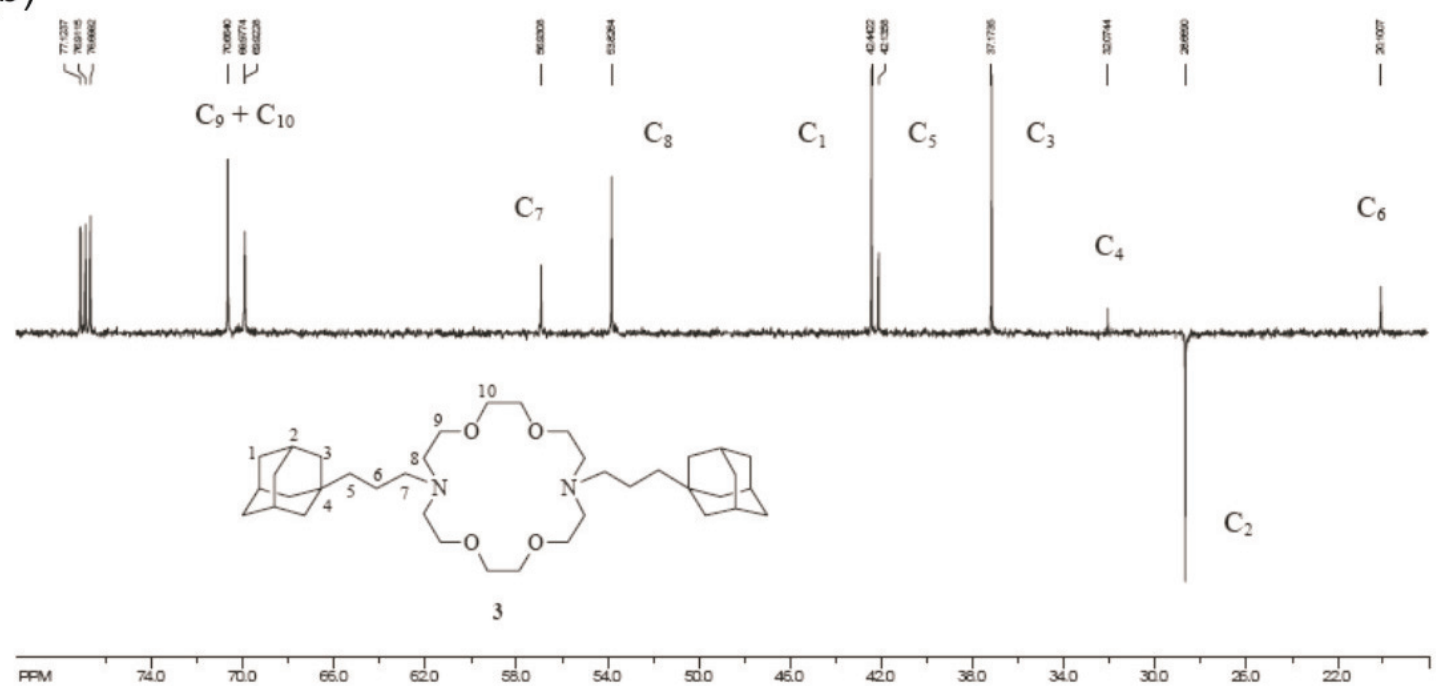

Figure 3. Comparison of the ${ }^{13} \mathrm{C}$ NMR spectra of lariat diaza-crown ethers 6 and 3 .

within $20 \mathrm{~kJ} / \mathrm{mol}$ energy window, Table 2) than in case of diaza-18-crown-6. Structures found within 10 $\mathrm{kJ} / \mathrm{mol}$ from the most stable conformation of compound 8 are distributed between 3 clusters. Each cluster can be represented with one cluster-representative structure. Visual inspection showed that only one of these three structures has appropriate orientation of oxygen and nitrogen atoms for complexation of alkali cations (Figure 4 and Figure S1 in Supplementary Materials). Comparison of these results with the results of conformational analysis of diaza-18-crown-6, suggested that in case of $N, N^{\prime}$-dibenzodiaza-18-crown-6 preorganization is necessary for binding alkali cations and it can be achieved due to the larger conformational flexibility.
Conformational analysis showed that compounds $\mathbf{2}$ and $\mathbf{3}$ have larger conformational flexibility than the referent compounds 7 and 8 (178 and 113 structures were found within $10 \mathrm{~kJ} / \mathrm{mol}$ energy window, Table 2), and the conformations with oxygen and nitrogen atoms oriented towards the centre of the crown ether ring are highly present within the most stable conformations (Table 2, Figure 4). Cluster analysis of the conformations found within $10 \mathrm{~kJ} / \mathrm{mol}$ of the most stable conformation resulted with 3 clusters in case of compound 2 and 6 clusters in case of compound $\mathbf{3}$. Visual inspection identified 2 out of 3 cluster-representatives in case of compound 2 (Figure 4 and Figure S1 in Supplementary Materials) and 4 out of 6 cluster-representatives in case of compound 3 (Figure 4 and Figure S1 in Supplemen- 
Table 2. Monte Carlo conformational search of compounds 1-6 and referent compounds 7-8

\begin{tabular}{|c|c|c|c|c|c|c|}
\hline $\begin{array}{l}\text { Crown } \\
\text { ethers }\end{array}$ & $\begin{array}{c}\mathrm{NS}^{(\mathrm{a})} \text { within } \\
10 \mathrm{~kJ} / \mathrm{mol}\end{array}$ & $\begin{array}{c}\mathrm{NS}^{(\mathrm{b})} \text { within } \\
20 \mathrm{~kJ} / \mathrm{mol}\end{array}$ & $\begin{array}{c}N \text { of } \\
\text { clusters }{ }^{(\mathfrak{c})}\end{array}$ & $\begin{array}{l}\text { Conform. represented } \\
\text { by each cluster }(\%)^{(\mathrm{d})}\end{array}$ & $\begin{array}{c}\text { Conf. energy }{ }^{(\mathrm{e})} \\
(\mathrm{kJ} / \mathrm{mol})\end{array}$ & $\begin{array}{c}\begin{array}{c}\text { Solv. energy } \\
(\mathrm{kJ} / \mathrm{mol})\end{array} \\
\end{array}$ \\
\hline 1 & 46 & 513 & 2 & $\begin{array}{l}\text { 1-A } 89 \% \\
1-\text { B } 11 \%\end{array}$ & 482.5 & -55.2 \\
\hline 2 & 178 & 1517 & 3 & $\begin{array}{r}2-A 75 \% \\
2-B 24 \% \\
2-C 1 \%\end{array}$ & 477.7 & -66.8 \\
\hline 3 & 113 & 878 & 6 & $\begin{array}{r}\text { 3-A } 43 \% \\
\text { 3-B } 25 \% \\
\text { 3-C } 15 \% \\
\text { 3-D } 12 \% \\
\text { 3-E } 3 \% \\
\text { 3-F } 2 \%\end{array}$ & 479.9 & -65.6 \\
\hline 4 & 6 & 160 & 3 & $\begin{array}{l}\text { 4-A } 66 \% \\
\text { 4-B } 17 \% \\
\text { 4-C } 17 \%\end{array}$ & 495.3 & -67.2 \\
\hline 5 & 44 & 652 & 3 & $\begin{array}{r}\text { 5-A } 68 \% \\
\text { 5-B } 27 \% \\
\text { 5-C } 5 \%\end{array}$ & 461.4 & -72.4 \\
\hline 6 & 43 & 581 & 3 & $\begin{array}{l}\text { 6-A } 58 \% \\
\text { 6-B } 30 \% \\
\text { 6-C } 12 \%\end{array}$ & 457.0 & -77.4 \\
\hline 7 & 1 & 20 & 1 & 7-A $100 \%$ & 266.4 & -40.3 \\
\hline 8 & 94 & 1214 & 3 & $\begin{array}{r}\text { 8-A } 90 \% \\
\text { 8-B } 9 \% \\
\text { 8-C } 1 \%\end{array}$ & 314.12 & -69.1 \\
\hline
\end{tabular}

(a) Number of structures found within the energy window of $10 \mathrm{~kJ} / \mathrm{mol}$.

(b) Number of structures found within the energy window of $20 \mathrm{~kJ} / \mathrm{mol}$.

(c) Number of clusters found by the cluster analysis of the structures found within the energy window of $10 \mathrm{~kJ} / \mathrm{mol}$.

(d) Percentage of conformations found within the energy window of $10 \mathrm{~kJ} / \mathrm{mol}$ that are represented by each cluster; cluster structures have the same names as on the Figure S1 in Supplementary Materials.

${ }^{\text {(e) }}$ Force field energy of the energetically most favorable conformation found by the MC search.

(f) Solvation energy in chloroform for the energetically most favorable conformation.

tary Materials) as the structures capable of binding alkali cations due to orientation of oxygen and nitrogen atoms. Cluster analysis showed that these structures represent $25 \%$ and $53 \%$ of the conformations found within $10 \mathrm{~kJ} / \mathrm{mol}$ energy window in cases of compounds $\mathbf{2}$ and $\mathbf{3}$, respectively. These results lead to conclusion that in cases of compounds $\mathbf{2}$ and $\mathbf{3}$, the conformations with oxygen and nitrogen atoms in appropriate orientations for complexation of alkali cations are present and, due to the large conformational flexibility, any preorganization that might be needed for cation binding can easily occur. Consequence is that these compounds have larger complexation ability of alkali cations than the referent compounds $\mathbf{7}$ and $\mathbf{8}$ (Table 1, Figure 1).

Conformational analysis of compounds 1 and 4-6 revealed that these compounds have significantly lower conformational flexibility than the compounds $\mathbf{2}$ and $\mathbf{3}$, and lower conformational flexibility than dibenzodiazacrown 8 (Table 2). Conformational flexibility of compound $\mathbf{1}$ is decreased due to size of the linker through which adamantyl unit is attached to the crown ether ring. Planarity and rigidity of amide bond present in the linker decrease conformational flexibility of compounds 4-6. These results are in accordance with the ${ }^{13} \mathrm{C}$ NMR spectra where stable unsymmetrical conformation was observed in cases of compounds 4-6, while in cases of compounds $\mathbf{2}$ and $\mathbf{3}$ an average conformation was observed due to fast exchange of plenty different conformation (Figures 2 and 3). Cluster analyses of conformational searches of compounds $\mathbf{1}$ and 4-6 showed that conformations with oxygen and nitrogen atoms in appropriate orientation for complexation of alkali cations are rarely present within the most stable conformations (Figure S1). In case of compounds 4-6, conformations in which carbonyl oxygen from amide group is pointed towards ether ring were not found by the conformational searches (Figure S1). The later result suggests that carbonyl oxygen atom most probably does not participate in the binding of alkali cations. Thus, due to low conformational flexibility and low presence of stable preorganized conformations, compounds $\mathbf{1}$ and 4-6 have significantly lower ability of extraction of alkali cations 
2-B

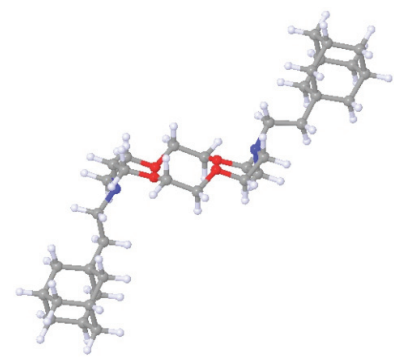

3-D

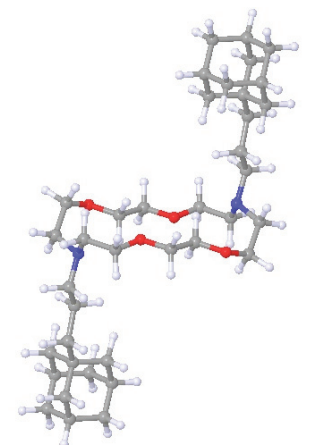

2-C

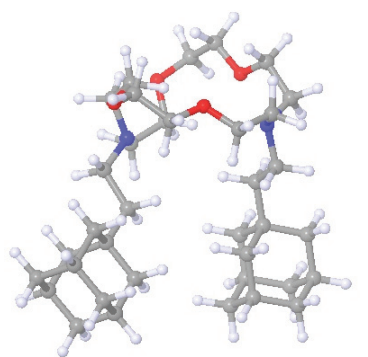

3-F

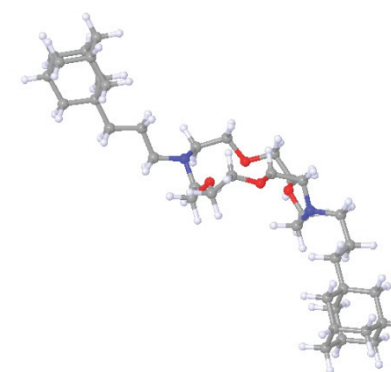

3-B

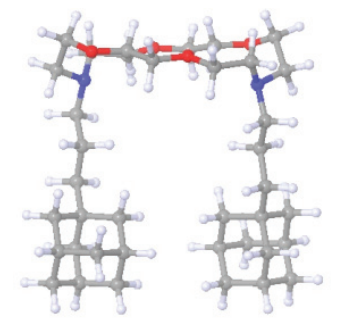

7-A

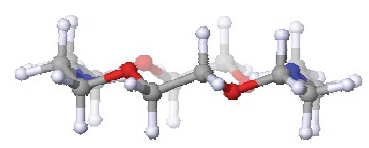

3-C

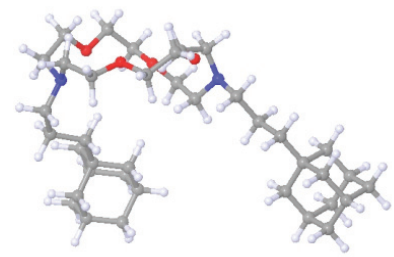

8-B

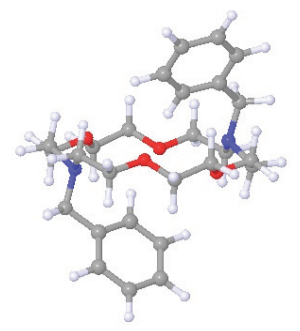

Figure 4. Cluster representative structures with oxygen and nitrogen atoms oriented towards the centre of the crown ether ring obtained by the cluster analysis of the conformations found within $10 \mathrm{~kJ} / \mathrm{mol}$ energy window of the compounds: 2, 3, 7 and $\mathbf{8}$. In case of compound 7, the only conformation that was found within $10 \mathrm{~kJ} / \mathrm{mol}$ energy window is shown. Cluster structures have the same names as in the Table 4 and on the Figure S1 in Supplementary Materials.

comparing to compounds $\mathbf{2}$ and $\mathbf{3}$ and lower extraction ability comparing to the referent compounds $\mathbf{7}$ and $\mathbf{8}$ (Table 1).

Since adamantane-functionalized receptors $\mathbf{2}$ and $\mathbf{3}$ showed a good ability to extract potassium and sodium cations we wanted to explore their transport abilities towards these two cations. How effectively the cation is transported with the host compound depends on how well it fits into the macrocyclic cavity and how easily it

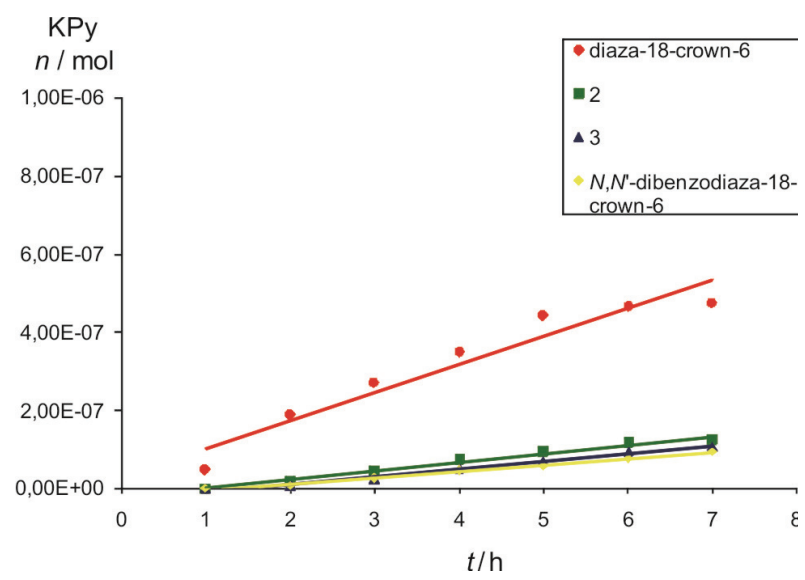

Figure 5. Transport of $\mathrm{KPy}$ through $\mathrm{CHCl}_{3}$ membrane containing diaza-crown ethers 2, 3, diaza-18-crown-6 (7) and $N, N^{\prime}$-dibenzo-diaza-18-crown-6 (8). can leave the host carrier at the membrane interface. ${ }^{20,27}$ The transport ability was studied using organic liquid membrane $\left(\mathrm{H}_{2} \mathrm{O}-\mathrm{CHCl}_{3}-\mathrm{H}_{2} \mathrm{O}\right)$ and compared with crown ethers 7 and $\mathbf{8}$. We also studied the transport rates for sodium and potassium picrate $\left(j_{\mathrm{c}}\right.$, in $\left.\mathrm{mol} \mathrm{h}^{-1}\right)$, and the results are shown in Table 2.

A plot of moles of cation transported into aqueous phase vs. time was constructed for each carriercontaining system. Linear concentration increase in the

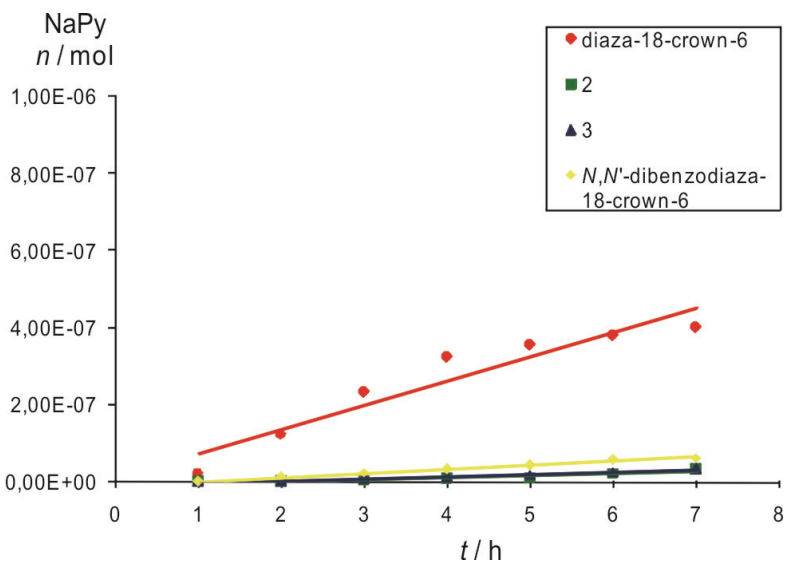

Figure 6. Transport of NaPy through $\mathrm{CHCl}_{3}$ membrane containing diaza-crown ethers 2, 3, diaza-18-crown-6 (7) and $N, N^{\prime}$-dibenzo-diaza-18-crown-6 (8). 
Table 3. Transport rate of $\mathrm{Na}^{+}$and $\mathrm{K}^{+}$picrate through chloroform membrane containing diaza-crown ethers 2, 3, 7 and 8

\begin{tabular}{ccccc}
\hline \multirow{2}{*}{ Crown ethers $^{(\mathrm{a})}$} & \multicolumn{2}{c}{$\left(j_{\mathrm{c}}\right)^{(\mathrm{b})} \mathrm{mol} \mathrm{h}^{-1} \times 10^{-8}$} & \multicolumn{2}{c}{$(n)^{(\mathrm{c})} \mathrm{mol} \times 10^{-7}$ in $24 \mathrm{~h}$} \\
\cline { 2 - 5 } & $\mathrm{Na}^{+}$ & $\mathrm{K}^{+}$ & $\mathrm{Na}^{+}$ & 1.57 \\
$\mathbf{2}$ & 0.54 & 2.19 & 0.64 & 1.44 \\
$\mathbf{3}$ & 0.57 & 1.94 & 0.70 & 6.62 \\
$\mathbf{8}$ & 6.28 & 7.19 & 4.17 & 2.19 \\
\hline
\end{tabular}

(a) Chloroform membrane contained $7.5 \times 10^{-4} \mathrm{~mol}$ of corresponding diaza-crown ether. The molar ratio of crown ether: $\mathrm{M}$ picrate was 1:10.

(b) Each value is the average of three independent measurements with deviation less than $\pm 5 \%$.

(c) Measured value.

receiving phase with increasing time was observed throughout the first 7 hours (Figures 5 and 6). In each case, the transport rate $\left(j_{c}\right)$ was obtained from the slope of the line. Similar linear increase in salt concentration in the receiving phase with increasing time was reported earlier. ${ }^{10 b, 20}$

Although bibracchial lariat ethers $\mathbf{2}$ and $\mathbf{3}$ are superior to diaza-18-crown-6 (7) and $N, N^{\prime}$-dibenzodiaza-18crown-6 (8) as alkali metal picrate extracting agents, the results obtained from transport experiments (Table 3, Figures 5 and 6) showed that the transport rates with lariat ethers $\mathbf{2}$ and $\mathbf{3}$ for $\mathrm{Na}^{+}$are lower compared to the referent compounds $\mathbf{7}$ and $\mathbf{8}$. The transport rates for $\mathrm{K}^{+}$ obtained with $\mathbf{2}$ and $\mathbf{3}$ are slightly larger than for the crown ether $\mathbf{8}$, but significantly lower than for the referent compound 7. However, the differences in the transport rates of $\mathrm{K}^{+} v s . \mathrm{Na}^{+}$picrates for both receptors, 2 and $\mathbf{3}$, are pronouncedly larger $(\approx 4$ times, Table 3$)$ compared to the referent crown ethers $\mathbf{7}$ and $\mathbf{8}$ and therefore, these compounds could be suitable for the selective transport of $\mathrm{K}^{+}$.

\section{CONCLUSIONS}

A series of bibracchial lariat ethers 1-6, with the adamantyl moiety as a part of the side-arm, has been synthesized and their cation-binding abilities have been assessed via their ability to extract alkali metal ions in comparison with the model compounds diaza-18-crown-6 (7) and $N, N^{\prime}$-dibenzodiaza-18-crown-6 (8). The results obtained by extraction experiments showed that the bibracchial lariat ethers 4,5 and 6 , in which the linkage of the adamantane side-arm to the diaza-18-crown-6 is realized by an amide bond, exhibited practically no extraction capabilities towards any of the alkali metal cations studied. However, lariat ethers $\mathbf{2}$ and $\mathbf{3}$, in which the adamantane side-arm is linked to the diaza-18-crown-6 by an amine bond, showed enhanced extraction capabilities for all cations compared to the parent crown ethers 7 and $\mathbf{8}$ as well as a significantly higher selectivity for $\mathrm{K}^{+}$ than diaza-crown 7. Conformational analysis suggested that the differences in cation-binding abilities of investigated compounds are mostly caused by the differences in their conformational flexibility. Compounds with higher conformational flexibility (estimated through number of structures found within $10 \mathrm{~kJ} / \mathrm{mol}$ and $20 \mathrm{~kJ} / \mathrm{mol}$ energy windows and cluster analysis) have larger extraction ability of alkali cations. Conformational analysis also showed that the presence of the amide group as the side arm linker decreases conformational flexibility of the compounds and, consequently, decreases their extraction abilities. The results obtained from the transport experiments showed that the transport rates of lariat ethers 2 and $\mathbf{3}$ for $\mathrm{K}^{+}$are larger than for the $N, N^{\prime}$-dibenzodiaza-18crown-6 (8), but significantly lower than for the diaza-18crown-6 (7). On the other hand, the differences in the transport rates of $\mathrm{K}^{+} v s . \mathrm{Na}^{+}$picrates, for both $\mathbf{2}$ and $\mathbf{3}$, are pronouncedly larger when compared to the referent crown ethers $\mathbf{7}$ and $\mathbf{8}$, what makes these compounds suitable for the selective transport of $\mathrm{K}^{+}$.

Supplementary Materials. - Supporting informations to the paper are enclosed to the electronic version of the article: Experimental procedures for the preparation of crown compounds 1-6, and ${ }^{1} \mathrm{H}$ and ${ }^{13} \mathrm{C}$ NMR spectra of all prepared compounds. These data can be found on the website of Croatica Chemica Acta (http://public.carnet.hr/ccacaa).

Acknowledgements. We gratefully acknowledge the financial support from the Ministry of Science, Education and Sports of the Republic of Croatia (grants no. 098-0982933-2911 and 098-1191344-2860).

\section{REFERENCES}

1. (a) C. J. Pedersen, J. Am. Chem. Soc. 89 (1967) 7017-7036; (b) C. J. Pedersen, J. Am. Chem. Soc. 92 (1970) 386-391.

2. (a) G. W. Gokel, Crown Ethers and Cryptands, Royal Society of Chemistry, Cambridge, 1991; (b) F. Vögtle, Supramolecular Chemistry, Wiley, New York, 1991; (c) J. M. Lehn, Supramolecular Chemistry: Concepts and Perspectives, VHC, Weinheim, 1995; (d) H.-J. Schneider and A. Yatsimirsky, Principles and Methods in Supramolecular Chemistry, Wiley, Chichester, 2000. 
3. (a) D. Parker, Macrocycle Synthesis: A Practical Approach, Oxford University Press, Oxford, 1996; (b) G. W. Gokel and S. J. Korzeniowski, Macrocyclic Polyether Synthesis, SpringerVerlag, Berlin, 1982; (c) J. J. Christensen, D. J. Eatough, and R. M Izatt, Chem. Rev. 74 (1974) 351-384; (d) R. D. Hancock and A. E. Martell, Chem. Rev. 89 (1989) 1875-1914.

4. (a) V. J. Gatto and G. W. Gokel, J. Am. Chem. Soc. 106 (1984) 8240-8244; (b) V. J. Gatto, K. A. Arnold, A. M. Viscariello, S. R. Miller, C. R. Morgan, and G. W. Gokel, J. Org. Chem. 51 (1986) 5373-5384; (c) K. E. Krakowiak, J. S. Bradshaw, and D. Zamecka-Krakowiak, J. Chem. Rev. 89 (1989) 929-972.

5. (a) G. W. Gokel, Chem. Soc. Rev. (1992) 39-47; (b) G. W. Gokel, L. J. Barbour, R. Ferdani, and J. Hu, Acc. Chem. Res. 35 (2002) 878-886; (c) L. D. Bratton, B. Strzelbicka, and R. A. Bartsch, Arkivoc XII (2003) 80-88.

6. (a) A. P. Marchand, Aldrichimica Acta 28 (1995) 95-104; (b) A. P. Marchand, K. A. Kumar, A. S. McKim, S. Alihodžić, H.-S. Chong, K. Krishnudu, M. Takhi, K. Mlinarić-Majerski, G. Kragol, and T. Šumanovac, Kem. Ind. 50 (2001) 129-138; (c) A. P. Marchand, J. S. Broadbelt, and K. Mlinarić-Majerski, Kem. Ind. 54 (2005) 89-98.

7. R. M. Moriarty, M. S. C. Rao, S. M. Tuladhar, C. D'Silva, G. Williams, and R. Gilardi, J. Am. Chem. Soc. 115 (1993) 1194-1196.

8. (a) K. Hayakawa, K. Kido, and K. Kanematsu, J. Chem. Soc. Chem. Commun. (1986) 268-269; (b) K. Hayakawa, K. Kido, and K. Kanematsu, J. Chem. Soc. Perkin. Trans. 1 (1988) 511-519; (c) K. Hayakawa, K. Kido, and K. Kanematsu, Heterocycles 27 (1988) 2293-2296.

9. (a) A. P. Marchand, Z. Huang, Z. Chen, H. K. Hariprakasha, I. N. N. Namboothiri, J. S. Broadbelt, and M. L. Reyzer, J. Heterocyclic Chem. 38 (2001) 1361-1368; (b) A. P. Marchand, H. Lai, B.-L. Deng, and J. Calderon, ARKIVOC V (2005) 7-20; (c) T. G. Levitskaia, B. A. Moyer, P. V. Bonnesen, A. P. Marchand, K. Krishnudu, Z. Chen, Z. Huang, H. G. Kruger, and A. S. McKim, J. Am. Chem. Soc. 123 (2001) 1209912100; (d) A. P. Marchand, Z. Huang, H. Lai, A. S. McKim, J. S. Brodbelt, and S. Williams, Heterocycles 62 (2004) 279-296; (e) A. P. Marchand, V. K. Gore, and G. Srinivas, Heterocycles 61 (2003) 541-550.

10. (a) A. P. Marchand, K. A. Kumar, A. S. McKim, K. MlinarićMajerski, and G. Kragol, Tetrehedron 53 (1997) 3467-3474; (b) K. Mlinarić-Majerski and G. Kragol, Tetrahedron 57 (2001) 449-457; (c) A. P. Marchand, A. Hazlewood, Z. Huang, S. Kumar Vadlakonda, J.-D. R. Rocha, T. D. Power, K. MinarićMajerski, L. Klaić, G. Kragol, and J. C. Bryan, Struct. Chem. 14 (2003) 279-288.

11. K. Mlinarić-Majerski and T. Šumanovac Ramljak, Tetrahedron 58 (2002) 4893-4898.

12. (a) G. W. Gokel, W. M. Leevy, and M. E. Weber, Chem. Rev. 104 (2004) 2723-2750; (b) W. M. Leevy, M. E. Weber, M. R. Gokel, G. B. Hughes-Strang, D. D. Daranciang, R. Ferdani, and G. W. Gokel, Org. Biomol. Chem. 3 (2005) 1647-1652.

13. (a) D.-J. van Unen, J. F. J. Engbersen, and D. N. Reinhoudt, Biotechnol. Bioeng. 77 (2002) 248-255; (b) T. Utoh, Y. Takagi, T. Murakami, Y. Hiyama, and H. Tsukube, J. Org. Chem. 61 (1996) 2158-2163; (c) D.-J. van Unen, I. K. Sakodinskaya, J. F. J. Engbersen, and D. N. Reinhoudt, J. Chem. Soc. Perkins Trans. 11998 3341-3343.

14. (a) M. Kralj, Lj. Tušek-Božić, and L. Frkanec, ChemMedChem 3 (2008) 1478-1492; (b) F. Supek, T. Šumanovac Ramljak, M. Marjanović, M. Buljubašić, G. Kragol, N. Ilić, T. Šmuc, D. Zahradka, K. Mlinarić-Majerski, and M. Kralj, E. J. Med. Chem. 46 (2011) 3444-3454.

15. (a) S. Vogel, K. Rohr, O. Dahl, and J. Wengel, Chem. Commun.
(2003) 1006-1007; (b) A. Basrak and H. Dugas, Tetrahedron Lett. 27 (1986) 3-6; (c) R. Fukuda, S. Takenaka, and M. Takagi, J. Chem. Soc. Chem. Commun. (1990) 10281030; (d) K. Brandt, R. Kruszynski, T. J. Bartczak, and I. PorwolikCzomperlik, Inorg. Chem. Acta 322 (2001) 138-144; (e) M. M. McPhee, J. T. Kern, B. C. Hoster, and S. M. Kerwin, Bioorg. Chem. 8 (2000) 98-118.

16. (a) W. M. Leevy, G. M. Donato, R. Ferdani, W. E. Goldman, P. H. Schlesinger, and G. W. Gokel, J. Am. Chem. Soc 124 (2002) 9022-9023; (b) S. Fernandez-Lopez, H.-S. Kim, E. C. Choi, M. Delgado, J. R. Granja, A. Khasanov, K. Kraehenbuehl, G. Long, D. A. Weinberger, K. M. Wilcoxen, and M. R. Ghadiri, Nature 412 (2001) 452-455.

17. I. Vujasinović, K. Mlinarić-Majerski, B. Bertoša, and S. Tomić, J. Phys. Org. Chem. 22 (2009) 431-437.

18. A. Tomašić, B. Bertoša, S. Tomić, M. Šoškić, and V. Magnus, $J$. Chromatogr. A 1154 (2007) 240-249.

19. (a) M. Ouchi, Y. Inoue, T. Kanzaki, and T. Hakushi, J. Org. Chem. 49 (1984) 1408-1412; (b) K. Kimura, T. Maeda, and T. Shono, Talanta 26 (1979) 945-949; (c) M. Ouchi, Y. Inoue, H. Sakamoto, A. Yamahira, M. Yoshinaga, and T. Hakushi, J. Org. Chem. 48 (1983) 3168-3173; (d) M. Ouchi, Y. Inoue, K. Wada, S. Iketani, T. Hakushi, and E. Weber, J. Org. Chem. 52 (1987) 2420-2427.

20. (a) M. Kirch and J.-M. Lehn, Angew. Chem. 87 (1975) 542-543; (b) J. D. Lamb, J. J. Christensen, S. R. Izatt, K. Bedke, M. S. Astin, R. and M. Izatt, J. Am. Chem. Soc. 102 (1980) 3399-3403; (c) J. D. Lamb, J. J. Christensen, J. L. Oscarson, B. L. Nielsen, B. W. Asay, and R. M. Izatt, J. Am. Chem. Soc. 102 (1980) 6820-6824; (d) R. M. Izatt, D. V. Dearden, P. R. Brown, J. S. Bradshow, J. J. Lamb, and J. D. Christensen, J. Am. Chem. Soc. 105 (1983) 1785-1790.

21. F. Mohamadi, N. G. J. Richards, W. C. Guida, R. Liskamp, M. Lipton, C. Caufield, G. Chang, T. Hendrickson, and W. C. Still, J. Comput. Chem. 11 (1990) 440-467.

22. (a) N. L. Allinger, Y. H. Yuh, and J.-H. Lii, J. Am. Chem. Soc. 111 (1989) 8551-8566; (b) J.-H. Lii and N. L. Allinger, J. Am. Chem. Soc. 111 (1989) 8566-8575; (c) J. -H. Lii and N. L. Allinger, J. Am. Chem. Soc. 111 (1989) 8576-8582.

23. W. C. Still, A. Tempczyk, R. C. Hawley, and T. Hendrickson, $J$. Am. Chem. Soc. 112 (1990) 6127-6129.

24. D. van der Spoel, E. Lindahl, B. Hess, G. Groenhof, A. E. Mark, and H. J. C. Berendsen, J. Comput. Chem. 26 (2005) 1701-1718.

25. M. Kralj, K. Majerski, T. Šumanovac Ramljak, and M. Marjanović, Adamantane derivatives of aza-crown ethers and their use in the treatment of tumor, WO 2010/146404 A1, Chem. Abstr. 154 (2010) 64876.

26. Synthesis of adamantane compounds: (a) 1-(2-tosyloxyethyl)adamantane: J. G. Henkel, J. T. Hane, and G. Gianutsos, J. Med. Chem. 25 (1982) 51-56; (b) 1-(3-tosyloxypropyl)adamantane: K. Mlinarić-Majerski, and T. Šumanovac Ramljak, Tetrahedron $\mathbf{5 8}$ (2002) 48934898; (c) 1 -adamantanecarbonyl chloride: H. Stetter, M. Schwartz, and A. Hirschhorn, Chem. Ber. 92 (1959) 1629-1635; (d) 1-(chloroethanoyl)adamantane: W. Lunn, W. Podmore, and S. Szinai, J. Chem. Soc. C 1968 1657-1660; (e) 1(chloropropanoyl)adamantane: W. Oppolzer and R. Moretti, Tetrahedron 44 (1988) 5541-5552; (f) 4,13 -diaza-18-crown-6 and $N, N^{\prime}$-dibenzo-4,13-diaza-18-crown-6: (I) R. A. Schultz, B. D. White, D. M. Dishong, K. A. Arnold, and G. W. Gokel, J. Am. Chem. Soc. 107 (1985) 6659-6668, (II) V. J. Gatto, K. A. Arnold, A. M. Viscariello, S. R. Miller, C. R. Morgan, and G. W. Gokel, J. Org. Chem. 51 (1986) 5373-5384.

27. J. D. Lamb, R. M. Izatt, P. A. Robertson, and J. J. Christensen, $J$. Am. Chem. Soc. 102 (1980) 2452-2454. 